\title{
Caracterização, compatibilidade e ocorrência de reprodução sexual entre isolados de Pyricularia grisea de diferentes hospedeiros
}

\author{
Rafael Galbieri ${ }^{1}$, Alfredo Seiiti Urashima
}

Departamento de Biotecnologia Vegetal, Centro de Ciências Agrárias, Universidade Federal de São Carlos, Via Anhanguera Km 174, CEP 13600-

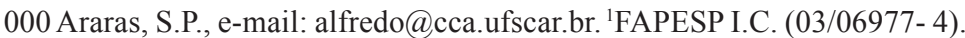

Autor para correspondência: Alfredo S. Urashima

Data de chegada:29/09/2005. Aceito para publicação em: 22/06/2007

\section{RESUMO}

Galbieri, R., Urashima, A.S. Caracterização, compatibilidade e ocorrência de reprodução sexual entre isolados de Pyricularia grisea de diferentes hospedeiros. Summa Phytopathologica, v.34, n.1, p.22-28, 2008

A brusone, causada por Pyricularia grisea (teleomorfa Magnaphorthe grisea), possui uma ampla gama de hospedeiros. No Brasil, arroz, trigo, triticale e cevada são as culturas que sofrem quedas significativas de produtividade devido ao ataque desse patógeno. Além desses cereais, outras gramíneas também têm apresentado sintomas dessa doença. Os objetivos dessa pesquisa foram: a) caracterizar sexualmente isolados de $P$. grisea desses hospedeiros baseado na determinação do "mating type", fertilidade, sexualidade, compatibilidade sexual, b) analisar o grau de compatibilidade sexual entre isolados de brusone de trigo e de outras gramíneas, c) estudar a ocorrência da reprodução sexual em isolados de trigo. Os resultados obtidos através de ensaios "in vitro" constataram: 1) compatibilidade sexual de $P$. grisea do trigo com Bromus catharticus, Phalaris canariensis e X. triticosecal; 2) desbalanço entre porcentagem de MAT1-1 e MAT1-2, com predominância de MAT1-1 na população de P. grisea do trigo; 3) existência de um campo de isolados de trigo com baixa habilidade de cruzamento; 4) baixa possibilidade de ocorrência de reprodução sexual de $P$. grisea em campos de trigo, mesmo com existência de ambos "mating type" num mesmo campo.

Palavras chave: brusone, hospedeiros, recombinação, Magnaporthe grisea

\section{ABSTRACT}

Galbieri, R., Urashima, A.S. Sexual characterization, compatibility and occurrence of sexual reproduction among isolates of Pyricularia grisea from different hosts. Summa Phytopathologica, v.34, n.1, p.22-28, 2008

The blast disease caused by Pyricularia grisea (teleomorph Magnaporthe grisea) has a wide host range. In Brazil, significant yield loss has been reported in rice, wheat, triticale and barley crops. Besides those cereals, several other gramineous plants have been shown to develop symptoms of this disease. The objectives of this research were: a) sexually characterize isolates of $P$. grisea from these hosts based on the mating type, fertility, sexuality, sexual compatibility, b) to analyze the degree of sexual compatibility among isolates from wheat and other grasses, c) to verify the occurrence of sexual reproduction in isolates from wheat. Results of "in vitro" assay showed: 1) sexual compatibility of $P$. grisea of wheat with isolates of the fungus obtained from Bromus catharticus, Phalaris canariensis e X. triticosecale, 2) a skewed distribution of mating type, with predominance of MAT11,0020in blast population from wheat, 3 ) the existence of isolates of low crossing ability in a wheat field, 4) a low possibility of sexual recombination in wheat isolates despite the existence of both mating type in the same field.

Additional keywords: blast, hosts, recombination, Magnaporthe grisea

Pyricularia grisea Sacc (teleomorfa Magnaporte grisea (Hebert) Barr) é o agente causal da brusone, um patógeno que causa sintomas em mais de 50 espécies de gramíneas (17). Dentre os vários hospedeiros desse fungo, o arroz (Oryza sativa L.) é o mais importante, sendo a brusone de ocorrência generalizada nesse hospedeiro em praticamente todas as regiões produtoras no mundo. No Brasil em meados da década de 80 , surgiu o primeiro relato de ataque desse fungo em trigo em condições naturais (7). O potencial de dano dessa doença pôde ser observado através de várias pesquisas: Goulart \& Paiva (4) observaram queda de $51 \%$ do rendimento de grãos e incidência de $86 \%$ em campos de trigo no estado de Mato Grosso do Sul, Urashima \& Kato (23) verificaram que não existiu nenhuma variedade resistente a todos os isolados do fungo.

Além desses dois cereais, no ano de 1995 foram observadas lavouras comerciais de triticale (X. Triticosecale) da região Centro-Sul do Paraná infectadas por P. grisea com danos de $60 \%$ na produtividade (14). Posteriormente, a brusone atingiu proporções epidêmicas em extensas áreas de triticale no estado de São Paulo no ano de 2001, com severas perdas na produtividade. Até então, essa cultura era uma alternativa interessante para a região Sul do Estado devido à maior rusticidade e resistência que o trigo, o que acarretava num custo menor de produção, visto que boa produtividade podia ser obtida sem que nenhuma pulverização com produtos químicos fosse necessária (na região, a cultura do trigo necessitava de duas pulverizações).

A cevada (Hordeum vulgare L.) foi um outro cereal que apresentou sintomas de brusone no Brasil. Essa doença foi verificada pela primeira vez em 1998 em condições naturais na região de Brasília, sem que, no entanto, maiores detalhes tenham sido abordados (1). Mais 
recentemente a doença foi constatada em azevém (Lolium multiflorum Lam.), uma importante gramínea utilizada em pastagens no sul do país, com prejuízos de até $100 \%$ em determinadas áreas de produção de sementes no Rio Grande do Sul (16).

Esses relatos comprovam o alto grau de variação patogênica desse fungo. O mecanismo responsável por este fenômeno é ainda muito discutido. Variação no número de cromossomos, recombinação parassexual e transposição foram citadas como fontes primárias dessa variação $(11,17,30)$. Recombinação sexual em $P$. grisea era considerada extremamente rara porque isolados de arroz coletados no campo tinham baixa fertilidade sexual $(10,15)$ e os estudos sobre a distribuição de tipos compatíveis mostraram que somente um tipo compatível ("mating type") predominava numa determinada região rizícola $(10,29)$. No entanto, recentes descobertas de isolados de alta fertilidade, hermafrodita, de ambos "mating type", próximo ao centro de origem do arroz sugerem que a recombinação sexual pode contribuir para a variabilidade genética desse fungo $(5,11,13)$. A existência da fase sexual é considerada vantajosa devido a maior capacidade de gerar diversidade genética através da meiose, o que conseqüentemente tem importância direta nas estratégias de controle de doenças.

A fase perfeita de $P$. grisea foi primeiramente encontrada cruzando- se dois isolados do fungo obtidos de Digitaria sanguinalis (L.) Scop sob condições de laboratório, demonstrando sua caracteristica heterotálica (6). Em seguida, o estágio sexual do fungo de outros cereais e gramíneas foram produzidos com sucesso (19) e finalmente a teleomorfa do fungo proveniente de arroz foi reportado $(9,28)$. Além de meio artificial, o teleomorfa de $P$. grisea pode ser facilmente produzido através da co-inoculação de isolados compatíveis em tecido morto de plantas de arroz ou in vitro, sobre plantas sadias $(5,18)$. Tentativas para se determinar a existência da fase sexual no campo examinaram a porcentagem de distribuição dos tipos compatíveis ("mating type"). Isso porque um gene com dois alelos, denominados MAT1-1 e MAT1-2, controla o tipo compatível em P. grisea, e a reprodução sexual pode produzir progênies de ambos "mating type" em igual proporção (15). Portanto, se essa distribuição for igual ('random mating") existiria um alto indicativo da ocorrência de reprodução sexual na população.

A despeito da importância da doença e do grande número de culturas e ervas daninhas ser infectada por $P$. grisea no Brasil, pouca pesquisa tem sido feita sobre esse assunto. Os poucos estudos sobre sexualidade do fungo enfocaram a compatibilidade sexual de um número limitado de isolados de $P$. grisea de trigo e de outros hospedeiros e verificaram

Tabela 1. Identificação dos campos de coleta, hospedeiro de origem, número de isolados, local e data de coleta de Pyricularia grisea.

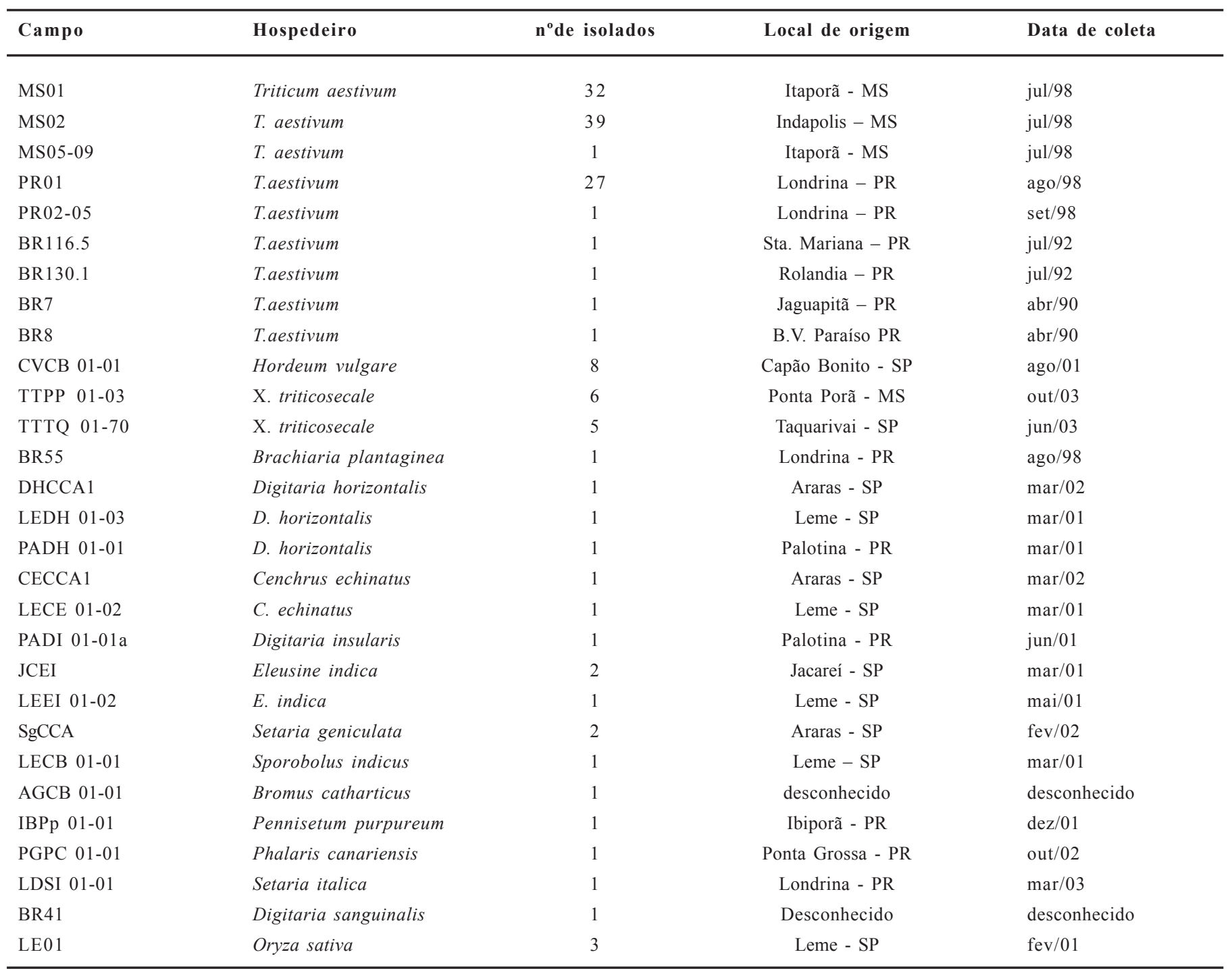


que o patógeno do trigo somente cruzou com o de Brachiaria plantaginea e que isolados de arroz tiveram baixa fertilidade e inabilidade de cruzar (21). Por outro lado, isolados do trigo mostraram alta habilidade de cruzamento sexual, sendo hermafroditas, com presença de ambos os tipos compatíveis num mesmo campo ao mesmo tempo $(2,21)$. Devido a capacidade de $P$. grisea de produzir peritécio envolver características complexas (25), a fertilidade e capacidade de cruzamento foram usadas como critério para diferenciar os patógenos causadores da brusone do trigo e do arroz (21). Poucos trabalhos enfocando os aspectos sexuais de isolados da brusone de outros hospedeiros no Brasil tem sido realizados $(2,21)$.

O presente estudo teve os objetivos de determinar as características sexuais de isolados de $P$. grisea de arroz, trigo, triticale, cevada, pastagens e ervas daninhas, bem como sua compatibilidade com isolados do trigo. Em seguida, estudar a ocorrência de reprodução sexual em $P$. grisea do trigo através da distribuição do "mating type" em três diferentes campos.

\section{MATERIAL E MÉTODOS}

\section{1 - Patógeno}

Isolados monospóricos de $P$. grisea utilizados neste estudo foram obtidos de lesões típicas de brusone em arroz (Oryza sativa L.), trigo (Triticum aestivum L.), triticale ( $X$. triticosecale Wittmack), aveia (Hordeum vulgare L.), campim marmelada (Brachiaria plantaginea (Link) Hitchc.), cevadinha (Bromus catharticus Vahl), capim carrapicho (Cenchrus echinatus L.), capim amargoso (Digitaria insularis (L.) Fedde), capim milhã (D. sanguinalis (L.) Scop.), capim colchão (D. horizontalis Willd.), capim pé-de-galinha (Eleusine indica (L.) Gaertn.), capim elefante (Pennisetum purpureum Schumach.), alpiste (Phalaris canariensis L.), capim rabo-de-raposa (Setaria geniculata P. Beauv.), S. italica (L.) Beauv. e capim moirão (Sporobolus indicus (L.) R. Br.), coletados nos Estados de São Paulo, Paraná e Mato Grosso do Sul (Tabela 1). Os isolados monospóricos de $P$. grisea desses materiais vegetais estão preservados em sílica gel a $5{ }^{\circ} \mathrm{C}$ no Laboratório de Genética Molecular do CCA, UFSCar, Araras.

\section{2 - Caracterização sexual de Pyricularia grisea}

A caracterização sexual englobou os seguintes parâmetros: escolha dos isolados parentais, determinação do "mating type", sexualidade, fertilidade e produção de órgãos sexuais (peritécia, ascas e ascósporos).

2.1 - Escolha dos isolados parentais. Três conjuntos distintos de isolados foram selecionados como parentais para determinação das características sexuais de diferentes hospedeiros: PR02-5 (MAT1-1) X MS05-9 (MAT1-2); BR130.1 (MAT1-1) X BR116.5 (MAT1-2) e BR7 (MAT1-2) X BR8 (MAT1-1), todos eles provenientes do trigo. Para determinação das características sexuais dos diversos campos de trigo foi empregado somente um conjunto de isolados como parentais: PR02-5 X MS05-9.

2.2 - Determinação do "mating type". O método empregado para a determinação do tipo compatível foi o "three-point culture" (8), onde fragmentos de micélio dos parentais e um do isolado de P. grisea de "mating type" desconhecido, foram colocados aproximadamente 4 $\mathrm{cm}$ distante entre si, em forma de triângulo, em placa de petri com meio de aveia. Esses cruzamentos foram mantidos a $22{ }^{\circ} \mathrm{C}$ sob luz fluorescente contínua. Cada cruzamento foi repetido pelo menos duas vezes. O tipo compatível foi determinado após 30 dias entre os isolados compatíveis sexualmente, caracterizado pela formação de peritécios. Isolados MAT1-1 foram aqueles que cruzaram com o parental MAT1-
2, e MAT1-2 quando cruzaram com MAT1-1. Isolados que não cruzaram com nenhum dos parentais foram denominados como N.D. (não determinado).

2.3 - Sexualidade. Os isolados foram classificados como fêmea, macho ou hermafrodita. Isolados considerados fêmea foram aqueles que formaram uma única banda de peritécio no seu próprio lado, machos foram os que formaram uma única banda de peritécio do lado oposto do isolado, ou seja, do lado do parental, e isolado hermafrodita aqueles que formaram duas fileiras de peritécio paralelas na linha de intersecção do crescimento micelial (8). Isolados que não produziram peritécio, não tiveram sua sexualidade determinada (N.D.)

2.4 Fertilidade. A fertilidade dos isolados de P. grisea foi determinada pelo número de peritécios formados em $25 \mathrm{~mm}^{2}$ através da metodologia utilizada por Bruno \& Urashima (2). Os isolados foram classificados em alta fertilidade (acima de 20 peritécios $/ 25 \mathrm{~mm}^{2}$ ), média (10 a 19 peritécios $/ 25 \mathrm{~mm}^{2}$ ) e baixa (menos que 10 peritécios/ $25 \mathrm{~mm}^{2}$ ). Os isolados que não produziram peritécio foram classificados como inférteis (I).

2.5 Produção de órgãos sexuais. Peritécios maduros foram retirados do meio de aveia e colocados em lâminas de vidro, com uma gota de água destilada, e rompidas posteriormente, sob lupa. Em seguida, a presença de ascas e ascósporos foi verificada em microscópio.

\section{3 - Compatibilidade Sexual.}

Esse parâmetro foi analisado entre isolados de $P$. grisea de trigo com o de outros hospedeiros, já que todos os isolados parentais empregados para a caracterização sexual foram provenientes de trigo. Após o exame da formação de todos os órgãos sexuais, ascas e ascósporos foram liberados da peritécia e sua viabilidade verificada em água.

\section{4 - Análise da ocorrência de reprodução sexual}

Esse exame foi feito através da distribuição da porcentagem dos tipos compatíveis (MAT1-1 e MAT1-2) em campos de trigo que apresentassem alta capacidade de cruzamento sexual.

Para o estudo de caracterização sexual foram empregados 28 isolados de $P$. grisea de 15 hospedeiros diferentes. Para a análise de reprodução sexual foram avaliados 32, 39 e 27 isolados coletados de três campos distintos de trigo: MS01, MS02 e PR01.

\section{RESULTADOS E DISCUSSÃO}

Dentre os 28 isolados obtidos de 15 espécies diferentes de hospedeiros, somente seis isolados cruzaram sexualmente com pelo menos um dos isolados de trigo empregados como parentais. Dos 15 hospedeiros, somente cinco (B. plantaginea, B. catharticus, $P$. canariensis, $X$. triticosecale e $D$. horizontalis) tiveram suas características sexuais determinadas (Tabela 2). X. triticosecale e $D$. horizontalis foram representados por mais de um isolado e mostraram características diferentes em função do isolado, já que dois isolados de triticale de um total de quatro e um de três isolados de $D$. horizontalis tiveram seu "mating type" conhecido; em ambos hospedeiros dois isolados não cruzaram com nenhum dos parentais. Essa variação no comportamento sexual dos isolados de uma mesma espécie mostra que existe variabilidade genética do fungo dentro de uma mesma espécie vegetal mesmo, que esses fungos venham de ervas daninhas. Outros isolados de ervas daninhas que não tiveram o "mating type" conhecido por não cruzarem com nenhum dos isolados empregados foram $C$. echinatus, D. insularis, D. sanguinalis, E. indica, Setaria geniculata, 
Tabela 2. Características sexuais ("mating type", sexualidade, fertilidade e produção de órgãos sexuais) de Pyricularia grisea de 15 diferentes espécies de hospedeiros, utilizando três diferentes conjuntos de parentais provenientes de trigo.

\begin{tabular}{|c|c|c|c|c|c|c|}
\hline & $n^{0}$ de isolados & "Mating type" & Parentais $^{1}$ & Sexualidade & Fertilidade $^{2}$ & Orgãos sexuais $^{3}$ \\
\hline Brachiaria plantaginea & 1 & $M A T 1-2$ & BR 8 & MACHO & ALTA & $\mathrm{P}$ \\
\hline Bromus catharticus & 1 & $M A T 1-2$ & BR 8 & MACHO & ALTA & $\mathrm{P}, \mathrm{A}, \mathrm{AS}$ \\
\hline Phalaris canariensis & 1 & $M A T 1-2$ & BR 8 & MACHO & ALTA & $\mathrm{P}, \mathrm{A}, \mathrm{AS}$ \\
\hline X. triticosecale & 4 & 2 MAT1-2 e 2 N.D. ${ }^{4}$ & BR8 e BR130.1 & MACHO & ALTA & $\mathrm{P}, \mathrm{A}, \mathrm{AS}$ \\
\hline Digitaria horizontalis & 3 & 1 MAT1-1 e 2 N.D. & MS05-9 & $\mathrm{MACHO}$ & MÉDIA & $\mathrm{P}$ \\
\hline Cenchrus echinatus & 2 & N.D. & - & N.D. & I. 5 & - \\
\hline Digitaria insularis & 1 & N.D. & - & N.D. & I. & - \\
\hline Eleusine indica & 3 & N.D. & - & N.D. & I. & - \\
\hline Setaria geniculata & 1 & N.D. & - & N.D. & I. & - \\
\hline Sporobolus indicus & 1 & N.D. & - & N.D. & I. & - \\
\hline Pennisetum purpureum & 1 & N.D. & - & N.D. & I. & - \\
\hline Setaria italica & 1 & N.D. & - & N.D. & I. & - \\
\hline Digitaria sanguinalis & 1 & N.D. & - & N.D. & I. & - \\
\hline Hordeum vulgare & 4 & N.D. & - & N.D. & I. & - \\
\hline Oryza sativa & 3 & N.D. & - & N.D. & I. & - \\
\hline
\end{tabular}

${ }^{1}$ Parentais (BR8 X BR7, BR130.1 X BR116.5, PR02-05 X MS05-09); ${ }^{2}$ Número de peritécios em $25 \mathrm{~mm}{ }^{2}:<10=$ baixo, 10 a $19=$ médio e $>19=$ alto; ${ }^{3} \mathrm{P}$ $=$ Peritécio, $\mathrm{A}=$ Ascas; $\mathrm{As}=$ ascosporos; ${ }^{4} \mathrm{~N} . \mathrm{D} .=$ não determinado; ${ }^{5} \mathrm{I} .=$ infértil

S. italica, $S$. indicus e $P$. purpureum, não permitindo que qualquer inferência sobre "mating type" ou outras características sexuais pudesse ser feita. Estudos sobre sexualidade de $P$. grisea de outros hospedeiros que não o arroz também foram realizados no Japão e Índia $(26,27,28)$, mas nenhuma relação com esses trabalhos pode ser feita devido à diferença entre as espécies hospedeiras e os isolados parentais empregados. Estudos anteriores realizados com isolados brasileiros de $P$. grisea, também observaram um grande número de isolados de ervas daninhas que não cruzaram com nenhum dos vários parentais $(2,21)$, demonstrando que a grande maioria de $P$. grisea que atacam ervas daninhas possui baixa capacidade de cruzamento, contrariamente do sugerido por Yaegashi \& Nishihara (28). Dentre os isolados que cruzaram sexualmente, a grande maioria foi de MAT1-2 (B. platanginea, $B$. catharticus, $P$. canariensis e $X$. triticosecale) já que somente o isolado de D. horizontalis foi MAT1-1, mas estudo anterior já havia identificado MAT1-2 nesse ultimo isolado (21), demonstrando que não existe predominância de nenhum "mating type" específico.

Não foi possível determinar o "mating type" de nenhum dos isolados de arroz testados, mesmo com os três parentais utilizados, demonstrando baixa habilidade de cruzamento de $P$. grisea do arroz. O comportamento sexual dos três isolados de arroz era esperado, já que isolados de arroz foram caracterizados no mundo todo por possuir baixa capacidade de cruzamento $(2,3,18,31)$. Isolados de cevada se comportaram da mesma maneira, ou seja, não tiveram seu tipo compatível determinado.

Se "mating type" pode ser considerado um critério útil para examinar o relacionamento entre isolados de $P$. grisea porque a produção de peritécio representa um fenômeno complexo com envolvimento de diferentes genes (25), o fato de nenhum isolado de arroz e cevada não ser compatível sexualmente com nenhum dos isolados de trigo, sugere que esses isolados são diferentes geneticamente. A diferenciação genética entre isolados de arroz e trigo já está bem documentada $(22,24)$, mas estudos mais detalhados sobre a relação entre isolados de trigo e cevada são necessários, visto que Urashima et al. (20) observaram similaridade genética entre alguns isolados desses dois cereais.

Dos isolados obtidos dessa gramínea e que tiveram o "mating type" determinado, todos tiveram sexualidade de macho. A característica macho está de acordo com as observações de que a maioria dos ascomicetos são fêmeas estéreis (31). Esta característica é explicada porque a fertilidade feminina é geneticamente complexa e qualquer mutação simples que ocorra pode resultar na esterilidade feminina, ao passo que a característica macho, por ser mais simples tanto fisiológica como geneticamente, está menos propensa a perda por mutações ao acaso (12). A despeito de serem machos, o número de peritécios formados foi alto, demonstrando alta fertilidade desses isolados, com número de peritécios observados em $25 \mathrm{~mm}^{2}$ superior a 19. Dentre eles, isolados de $B$. catharticus, $P$. canariensis e $X$. triticosecale tiveram formação de peritécio, ascas e ascósporos demonstrando uma maior compatibilidade genética entre isolados desses hospedeiros e do trigo em relação aos isolados que formaram somente peritécio, já que a formação de cada um desses órgãos é regida por um sistema genético complexo e independente, com envolvimento de diferentes genes (31).

Dos três conjuntos de parentais empregados, o BR8 foi o mais eficiente, permitindo a determinação do "mating type" de quatro dos seis isolados. Esse isolado não havia sido o melhor em estudo anterior (2) e demonstra que a escolha do isolado a ser empregado como parental é uma missão difícil visto que a formação de peritécio depende do isolado a ser pareado. Isso mostra a variação na capacidade de cruzamento entre isolados, demonstrando que, para esse tipo de análise interespecífica existe a necessidade de utilização de vários parentais para melhores resultados, concordando com a sugestão de Mekwatanakarn et al.(13).

As tabelas 3, 4 e 5 mostram as características sexuais de $P$. grisea de três diferentes campos de trigo. Na primeira tabela, 32 isolados de um único campo do Mato Grosso do Sul foram analisados (Tabela 3). Vinte e sete isolados $(84,4 \%)$ cruzaram com um dos parentais e 
Tabela 3. Características sexuais ("mating type”, sexualidade, fertilidade e produção de órgãos sexuais) de Pyricularia grisea de trigo do campo MS01.

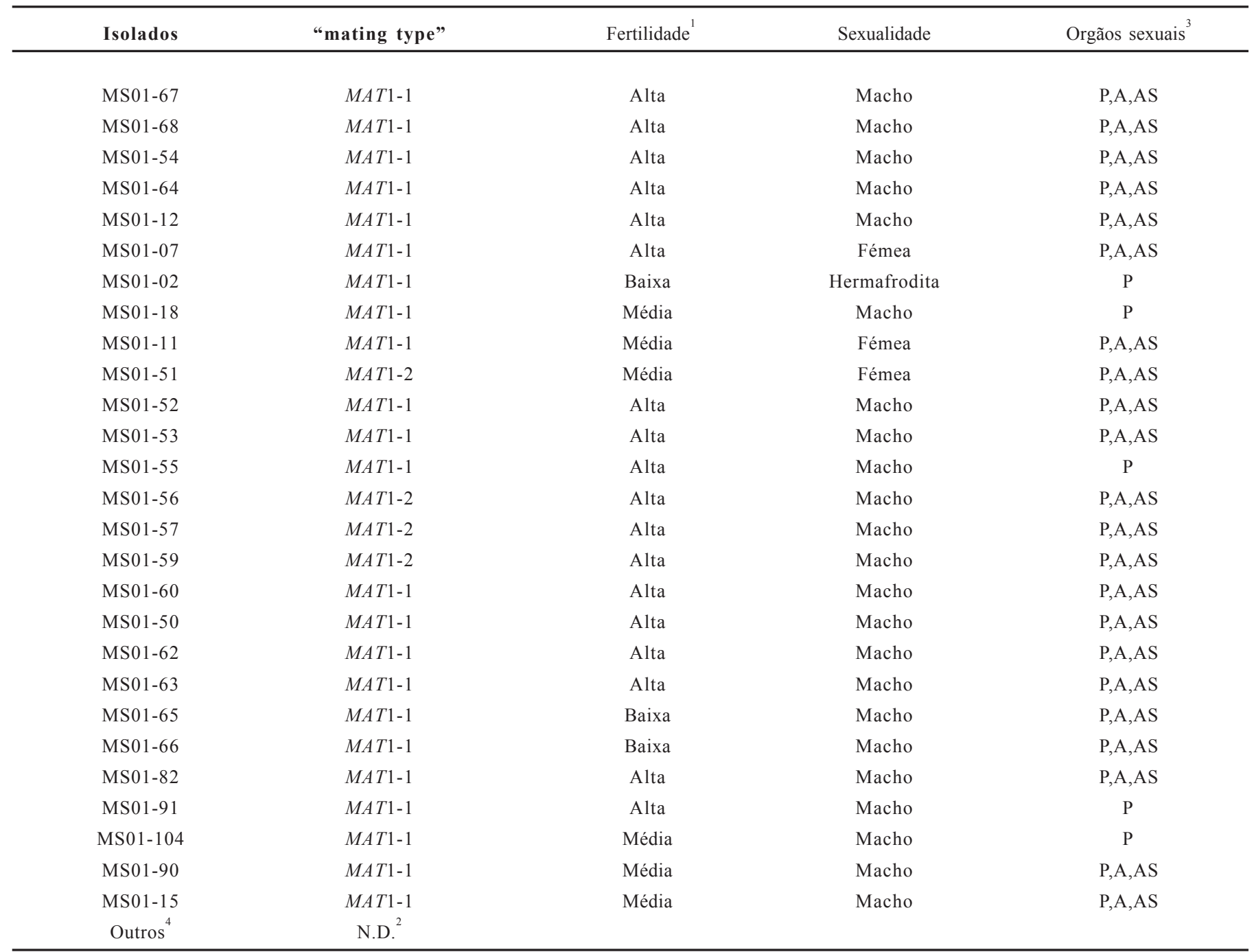

${ }^{1}$ Número de peritécios em 25mm²: 1-9 Baixa, 10-19 Média e acima de 19 Alta.

${ }^{2}$ N.D. = não determinado; ${ }^{3} \mathrm{P}=$ Peritécio, $\mathrm{A}=$ Ascas; As = ascósporos

'Outros: MS01-58, MS01-69, MS01-81, MS01-100, MS01-102

formaram peritécio, o que permitiu a identificação do "mating type". Essa alta porcentagem de isolados com "mating type" determinado está de acordo com as características de isolados de trigo estudados anteriormente que se caracterizaram por apresentarem uma alta capacidade de cruzamento $(2,21)$. Desses, a grande maioria foi de MAT1-1 (23 isolados ou 85,2\%) e somente quatro de MAT1-2 (14,8\%). A grande diferença nas porcentagens de MAT1-1 em relação ao MAT12 mostra que não existiu um equilíbrio de distribuição dos tipos compatíveis, e considerando a distribuição equilibrada entre os dois "mating type" um indício indireto da ocorrência de reprodução sexual na natureza (15), a possibilidade de que esteja ocorrendo reprodução sexual nesse campo é baixa.

A reprodução sexual não estar ocorrendo também com isolados do campo MS02. A diferença entre os campos MS01 (Tabela 3) e MS02 (Tabela 4) se refere a variedade de origem dos isolados e local de coleta dentro do estado de Mato Grosso do Sul (Tabela 1). Isolados do campo MS02 apresentaram uma capacidade intermediária de cruzamento, já que de 38 isolados empregados, 18 ou 47,4\% deles formaram peritécio e conseqüentemente tiveram seus "mating type" determinados e 20 isolados (52,6\%) não cruzaram com nenhum dos parentais. Daqueles, 14 isolados $(77,8 \%)$ foram MAT1-1 e quatro (22,2\%) MAT1-2. Também nesse campo, essa distribuição desuniforme dos tipos compatíveis sugere que a reprodução sexual não está ocorrendo.

Em ambos os campos, a maioria dos isolados foi classificada como macho, com formação de todos os órgãos reprodutivos, e uma menor porcentagem como isolados hermafroditas. Essa porcentagem de ocorrência de hermafroditas já era esperada, pois o hermafroditismo é altamente instável, perdendo rapidamente a fertilidade feminina (31), mas essas identificações permitem recomendar o emprego de tais isolados como parental em futura caracterização sexual de $P$. grisea no Brasil.

A Tabela 5 mostra as características sexuais de isolados de $P$. grisea de um campo de trigo de Londrina, PR. Esses resultados se mostraram inesperados, pois os isolados desse campo diferiram da maioria dos isolados de trigo estudados até o momento, no sentido de possuir baixa capacidade de cruzamento. Isolados de $P$. grisea de trigo são conhecidos como tendo uma alta capacidade de cruzamento e esse 
Tabela 4. Características sexuais ("mating type", sexualidade, fertilidade e produção de órgãos sexuais) de Pyicularia grisea de trigo do campo MS02.

\begin{tabular}{|c|c|c|c|c|}
\hline Isolados & mating type & Fertilidade $^{1}$ & Sexualidade & Orgãos sexuais $^{3}$ \\
\hline MS02-51 & $M A T 1-2$ & Alta & Macho & $\mathrm{P}, \mathrm{A}, \mathrm{AS}$ \\
\hline MS02-60 & $M A T 1-1$ & Alta & Macho & P,A,AS \\
\hline MS02-10 & $M A T 1-1$ & Baixa & Fémea & $\mathrm{P}$ \\
\hline MS02-15 & $M A T 1-1$ & Alta & Macho & P,A,AS \\
\hline MS02-62 & $M A T 1-1$ & Alta & Hermafrodita & $\mathrm{P}, \mathrm{A}$ \\
\hline MS02-73 & MAT1-1 & Baixa & Macho & $\mathrm{P}, \mathrm{A}, \mathrm{AS}$ \\
\hline MS02-76 & MAT1-1 & Baixa & Fémea & $\mathrm{P}, \mathrm{A}, \mathrm{AS}$ \\
\hline MS02-79 & $M A T 1-2$ & Média & Fémea & P,A,AS \\
\hline MS02-15 & MAT1-1 & Média & Macho & $\mathrm{P}, \mathrm{A}, \mathrm{AS}$ \\
\hline MS02-104 & $M A T 1-1$ & Alta & Macho & $\mathrm{P}$ \\
\hline MS02-204 & $M A T 1-1$ & Média & Macho & $\mathrm{P}, \mathrm{A}, \mathrm{AS}$ \\
\hline MS02-202 & $M A T 1-1$ & Baixa & Macho & $\mathrm{P}, \mathrm{A}, \mathrm{AS}$ \\
\hline MS02-208 & $M A T 1-1$ & Média & Macho & $\mathrm{P}, \mathrm{A}, \mathrm{AS}$ \\
\hline Outros $^{4}$ & N.D. ${ }^{2}$ & & & \\
\hline
\end{tabular}

Número de peritécios em $25 \mathrm{~mm}^{2}$ : 1-9 Baixa, 10-19 Média e acima de 19 Alta.

${ }^{2}$ N.D. = não determinado; ${ }^{3} \mathrm{P}=$ Peritécio, $\mathrm{A}=$ Ascas; $\mathrm{As}=$ ascósporos

${ }^{4}$ Outros: MS02-52, MS02-55, MS02-50, MS02-59, MS02-58, MS02-57, MS02-61, MS02-63, MS02-64, MS02-71, MS02-72, MS02-75, MS02-14, MS02-100, MS02-101, MS02-102, MS02-103, MS02-200, MS02-205 e MS02-207.

Tabela 5. Características sexuais ("mating type", sexualidade, fertilidade e produção de órgãos sexuais) de Pyricularia grisea de trigo do campo PR01.

\begin{tabular}{|c|c|c|c|c|}
\hline Isolados & mating type & Fertilidade $^{1}$ & Sexualidade & Orgãos sexuais $^{2}$ \\
\hline PR01-27 & $M A T 1-1$ & Alta & Macho & $\mathrm{P}, \mathrm{A}, \mathrm{AS}$ \\
\hline
\end{tabular}

${ }^{1}$ Fertilidade $=$ Número de peritécios em $25 \mathrm{~mm}^{2}$ : 1-9 Baixa, 10-19 Média e acima de 19 Alta; ${ }^{2} \mathrm{P}=$ Peritécio, A = Ascas; As = ascósporos; ${ }^{3} \mathrm{~N} . \mathrm{D} .=$ Não determinado; ${ }^{4}$ Outros $=$ PR01-39, PR01-40, PR01-04, PR01-84, PR01-38, PR01-36, PR01-89, PR01-43, PR01-34, PR01-101, PR01-85, PR01-16, PR01-23, PR01-70, PR01-43, PR01-21, PR01-16, PR01-113, PR01-40, PR01-71, PR01-81, PR01-95, PR01-91, PR01-114, PR01-98.

foi um dos parâmetros para a diferenciação com o patógeno do arroz $(2,21)$. Isolados de trigo desse campo se mostraram mais semelhantes aos isolados de arroz pois somente dois (ou 7,4\%) dos "mating type" foram identificados, comportando-se portanto como isolados de $P$. grisea do arroz que tem baixa capacidade de formar peritécio $(10,15,26)$. Embora somente dois isolados tenham cruzado, ambos "mating type" foram encontrados.

Em todos os três campos, os dois tipos compatíveis foram identificados no mesmo campo na mesma época, o que é uma condição imprescindível para a ocorrência de reprodução sexual em fungos heterotálicos. Além disso, em dois campos foram identificados isolados hermafroditas que, quando cruzados com isolados de trigo, formaram todos os órgãos sexuais viáveis (Tabelas 3 e 4). Esses fatores foram considerados por Zeigler (31) como condições necessárias para a recombinação sexual estar ocorrendo. Assim, mesmo que a distribuição de isolados MAT1-1 e MAT1-2 não esteja na proporção de 1:1, o que poderia sugerir a inexistência de reprodução sexual (15), tal possibilidade mereceria estudos mais detalhados, não podendo ser totalmente descartada porque a detecção de isolados fêmeas e hermafroditas nesses campos é um indicativo de reprodução sexual, já que é a meiose que mantém o complexo aparato genético da característica feminina (13). No campo PR01 (Tabela 5) nenhuma inferência sobre sexualidade pode ser feita devido a baixa capacidade de cruzamento de seus isolados, embora o isolado PR01-86 apresentasse alta formação de peritécios com formação de ascosporos viáveis e fertilidade feminina, todos atributos necessários para a ocorrência de reprodução sexual.

\section{REFERÊNCIA BIBLIOGRÁFICA}

1. Anjos, J.R.N.; Charchar, M.J.A. Natural infection of barley by Pyricularia grisea in Brazil. Fitopatologia Brasileira, Brasílila, v. 25, p. $205,2000$.

2. Bruno, A.C.; Urashima, A.S. Inter-relação sexual de Magnaporthe grisea do trigo com a brusone de outros hospedeiros. Fitopatolo- 
gia Brasileira, Brasília, v.26, p.21-26, 2001.

3. Dayakar, B.V.; Narayanan, N.N. Cross-compatibility and distribution of mating type alleles of the rice blast fungus Magnaporthe grisea in India. Plant Disease, St. Paul, v.84, p.700-704, 2000 .

4. Goulart, A.C.P.; Paiva, F.A. Perdas no rendimento de grãos de trigo causadas por Pyricularia grisea, nos anos de 1991 e 1992, no Mato Grosso do Sul. Summa Phytopathologica, Botucatu, v.26, p.279-282, 2000.

5. Hayashi, N.; Li, C.Y.; Li, J.L.; Naito, H. In vitro production on rice plants of perithecia of Magnaporthe grisea from Yunnan, China. Mycological Research, Cambridge, v.101, p.1308-1310, 1997.

6. Hebert, T.T. The perfect stage of Pyricularia grisea. Phytopathology, St. Paul, v.61, p.83-87, 1971.

7. Igarashi, S.; Utiamada, C.M.; Igarashi, L.C.; Kazuma, A.H.; Lopes, R.S. Pyricularia em trigo. 1. Ocorrência de Pyricularia sp. no estado do Parana. Fitopatologia Brasileira, Brasília, v.11, p.351-352, 1986 .

8. Itoi, S.; Mishima, T.; Arase, S.; Nozu, M. Mating behaviour of Japanese isolates of Pyricularia oryzae. Phytopatologhy, St. Paul, v.73, p.155-158, 1983.

9. Kato, H.; Yamaguchi, T.; Nishihara, N. The perfect state of Pyricularia oryzae Cav. in culture. Annals of the Phytopathological Society of Japan, Tokyo, v.42, p.507-510, 1976.

10. Kato, H.; Yamaguchi, T. The perfect state of Pyricularia oryzae Cav. from rice plants in culture. Annals of the Phytopathological Society of Japan, Tokyo, v.98, p.607-612, 1982.

11. Kumar, J.; Nelson, R.J.; Zeigler, R.S. Population structure and dynamics of Magnaporthe grisea in the Indian Himalayas. Genetics, Pittsburg, v.152, p.971-984, 1999.

12. Leslie, J.F.; Klein, K.K. Female fertility and mating type effects on effective population size and evolution in filamentous fungi. Genetics, Pittsburg, v.144, p.557-567, 1996.

13. Mekwatanakarn, P.; Kositratana, W.; Phromraksa, T.; Zeigler, R.S. Sexually fertile Magnaporthe grisea rice pathogens in Thailand. Plant Disease, St. Paul, v.83, p.939-943, 1999.

14. Mehta, Y.R.; Baier, A. Variação patogenica entre isolados de Magnaporthe grisea atacando triticale e trigo no estado do Paraná. Summa Phytopathologica, Botucatu, v.24, p.119-125, 1998.

15. Notteghem, J.L.; Silué, D. Distribution of mating type alleles in Magnaporthe grisea populations pathogenic on rice. Phytopathology, St. Paul, v.82, p.421-424, 1992.

16. Nunes, C.D.M.; Brancão, N.; Rodrigues, R.S.; Reis, J.C. Ocorrência de brusone no azevém em diferentes locais do RS, Brasil. Fitopatologia Brasileira, Brasília, v.27, p.231, 2002.

17. Ou, S.H. Blast. In: Ou, S.H. Rice diseases. $2^{\text {nd }}$. Wallingford, UK:
CAB International, 1985. p.109-201.

18. Silué, D.; Notteghem, J.L. Production of perithecia of Magnaporthe grisea on rice plants. Mycological Research, Cambridge, v.94, p.1151-1152, 1990.

19. Ueyama, A.; Tsuda, M. Formation of the perfect state in culture of Pyricularia sp. from some gramineous plants (preliminary report). Translaction of the Mycological Society of Japan, v.16, p.420-422, 1975.

20. Urashima, A.S.; Dias Martins, T.; Bueno, C.R.N.C.; Favaro, D.B.; Arruda, M.A.; Mehta, Y.R. Triticale and barley: new hosts of Magnaporthe grisea in São Paulo, Brazil - Relationship with blast of rice and wheat. In: Kawasaki, S. (Ed.). Rice Blast: Interaction with Rice and Control. Dordrecht. Kluwer Academic, 2004. p. $251-260$.

21. Urashima, A.S.; Igarashi, S.; Kato, H. Host range, mating type and fertility of Pyricularia grisea from wheat in Brazil. Plant Disease, St. Paul, v.77, p.1211 1216, 1993.

22. Urashima, A.S; Hashimoto, Y.; Don, L.D.; Kusaba, M.; Tosa, Y.; Nakayashiki, H.; Mayama, S. Molecular analysis in Brazil with a homologue of retransposon MGR583. Annals of the Phytopathological Society of Japan, Tokyo, v.65, p.429-436, 1999.

23. Urashima, A.S.; Kato, H. Varietal resistance and chemical control of wheat blast fungus. Summa Phytopathologica, Botucatu, v.20, p.107-112, 1994.

24. Valent, B. 1990. Rice blast as a model system for plant pathology. Phytopathology, St. Paul, v. 80, p.33-36, 1990.

25. Valent, B.; Leonard, F.; Chumley, F.G. Magnaporthe grisea genes for pathogenicity and virulence identified through a series of backcrosses. Genetics, Pittsburg, v.127, p.87-101, 1991.

26. Viji, G.; Gnanamanickam S.S. Mating type distribution and fertility status of Magnaoprthe grisea populations from various hosts in India. Plant Disease, St. Paul, v.82, p.36-40, 1998.

27. Yaegashi, H. On the sexuality of blast fungi, Pyricularia spp. Annals of the Phytopathological Society of Japan, Tokyo, v.43, p.432-439, 1977

28. Yaegashi, H.; Nishihara, N. Production of the perfect stage in Pyricularia from cereals and grasses. Annals of the Phytopathological Society of Japan, Tokyo, v.42, p.511-515, 1976.

29. Yaegashi, H.; Yamada, M. Pathogenic race and mating type of Pyricularia oryzae from Soviet Union, China, Nepal, Thailand, Indonesia, and Colombia. Annals of the Phytopathological Society of Japan, Tokyo, v.52, p.225-234, 1986.

30. Zeigler, R.S.; Scott, R.P.; Leung, H.; Bordeos, A.A.; Kumar, J.; Nelson, R.J. Evidence of parasexual exchange of DNA in the rice blast fungus challenges its exclusive clonality. Phytopathology, St. Paul, v.87, p.284-294, 1997.

31. Zeigler, R.S. Recombination in Magnaporte grisea. Annual Review of Phytopathology, Baltimore, v.36, p.249-275, 1998. 